\title{
Avaliação sensorial e da qualidade de uvas-passas processadas a partir de três cultivares produzidas no semiárido
}

\author{
Sensory and quality assessment of processed raisins from three cultivars produced in \\ the semiarid region of Brazil
}

\author{
Maristella Martineli1* (D), Fernando Teodoro Mendes' ${ }^{1}$, João Rafael Prudêncio dos Santos', \\ Camila Maida de Albuquerque Maranhão ${ }^{1}$, Ariane Castricini ${ }^{2}$ (D) \\ 1 Universidade Estadual de Montes Claros (UNIMONTES), Departamento de Ciências Agrárias, Janaúba/MG - Brasil \\ 2 Empresa Mineira de Pesquisa Agropecuária (EPAMIG), Nova Porteirinha/MG - Brasil
}

\section{${ }^{*}$ Corresponding Author}

Maristella Martineli, Universidade Estadual de Montes Claros (UNIMONTES), Departamento de Ciências Agrárias, Avenida Reinaldo Vianna, 2630, Bico da Pedra, CEP: 39440-000, Janaúba/MG - Brasil, e-mail: maristella.martineli@unimontes.br

Cite as: Sensory and quality assessment of processed raisins from three cultivars produced in the semiarid region of brazil. Braz. J. Food Technol., v. 21, e2017131, 2018

Received: Aug. 15, 2017; Approved: Apr. 30, 2018

\section{Resumo}

No semiárido, a viticultura vem se destacando de maneira expressiva, devido à sua capacidade de possibilitar que as plantas produzam significativamente durante todo o ano. A desidratação é uma alternativa eficiente para conservação de frutos, sendo um processo de fácil aplicação, que estende a vida de prateleira e agrega valor. Desta forma, estudar as cultivares de uvas produzidas nessa região para a produção de uvas-passas faz-se necessário, para verificar a possibilidade de se obter um produto de boa aceitação no mercado. Neste sentido, objetivou-se avaliar as características físicas, químicas e sensoriais de uvas 'Vitória', 'Niágara Branca' e 'Benitaka' desidratadas, produzidas no semiárido. O experimento foi conduzido no Laboratório de Tecnologia de Processamento de Produtos de Origem Vegetal (TPOV) da Universidade Estadual de Montes Claros, Campus Janaúba - MG. O Delineamento experimental aplicado foi o inteiramente casualizado, com três tratamentos (três cultivares de uvas: Vitória, Niágara Branca e Benitaka) e sete repetições (cada repetição foi composta por três cachos). As passas foram avaliadas quanto aos seguintes parâmetros: grau de umidade, rendimento, pH, sólidos solúveis, acidez titulável e aceitação sensorial. O produto processado a partir da 'Niágara' apresentou maior rendimento de processamento, enquanto 'Vitória' apresentou maior pH. A cultivar Benitaka se destacou por apresentar um produto com menor umidade e maiores teores de sólidos solúveis e acidez titulável. Quanto aos aspectos sensoriais, as uvas-passas provenientes das cultivares Vitória e Benitaka foram aceitas pelos consumidores em todos os atributos estudados. O produto obtido pela cultivar Niágara Branca foi rejeitado pelos consumidores.

Palavras-chave: Vitis vinifera L.; Processamento; Cultivares.

\section{Abstract}

In the semiarid region of Brazil, viticulture has been expressively highlighted due to its capacity to allow the plants to produce significantly throughout the year. Dehydration is an efficient alternative for fruit preservation, the process being easy to apply, extending the shelf life and aggregating value to the product. It is therefore necessary to study the grape cultivars produced in the region for the production of raisins, observing the possibility of obtaining a product acceptable on the market. Thus the objective of this work was to evaluate the physical, chemical and sensory characteristics of raisins produced from 'Vitória', 'Niágara Branca' and 'Benitaka' grapes in the semiarid region of Brazil. The experiment was carried out in the Technology Laboratory for the Processing of Vegetable Origin Products of the State University of Montes Claros, Campus Janaúba-MG, Brazil. The experimental design was completely randomized, with three treatments (three grape cultivars: Vitória, Benitaka and Niágara Branca) and seven replicates (each replicate composed of three bunches of grapes). The raisins were evaluated for their moisture contents, yield, $\mathrm{pH}$, soluble solids, titratable acidity and sensory acceptance. 
The product processed from 'Niagara Branca' presented the highest processing yield, while that from 'Vitoria' showed the highest $\mathrm{pH}$ value. The Benitaka cultivar stood out for presenting a product with a lower moisture content, higher soluble solids content and higher titratable acidity. As for the sensory aspects, the raisins from the Vitória and Benitaka cultivars were accepted by consumers for all the attributes studied. The product obtained from the Niágara Branca cultivar was rejected by the consumers.

Keywords: Vitis vinifera L.; Processing; Cultivars.

\section{Introdução}

Pertencente à família botânica Vitaceae, a uva Vitis vinifera apresenta grandes quantidades de compostos fenólicos, que, além de atribuir características sensoriais à fruta, possuem, segundo Mattos et al. (2016), propriedades funcionais e alto potencial antioxidante e antimicrobiano.

No Brasil, a viticultura (temperada) tradicional na Região Sul e em regiões de altitude da Região Sudeste do Brasil expandiu-se para as regiões que possibilitam a viticultura tropical, como o Vale do Submédio São Francisco, o noroeste Paulista e o norte de Minas Gerais (CAMARGO et al., 2011). Hoffmann (2005) citou que a adaptação da videira a diferentes climas, juntamente com o controle da irrigação em regiões com característica de poucas chuvas, possibilitou o cultivo de cultivares de uva de mesa para regiões de clima tropical.

De acordo com dados do IBGE (2017), em 2016, no Brasil, a produção de uva alcançou valores de cerca de 987 mil toneladas. No ano anterior, Mello (2016) reportou que $52,12 \%$ da produção de uva daquele ano, no país, foi destinada ao processamento, em especial, nas formas de vinho, suco e derivados, e o restante, para o consumo in natura. Já o volume processado desta fruta na forma seca ainda continua baixo, confirmado pelos dados da VITIBRASIL (2016), mostrando que, em 2015, o Brasil importou dos países também produtores de uva, como Argentina, EUA, Chile, Emirados Árabes e Irã, um total de cerca de 24,8 toneladas de uva-passa, totalizando gasto de cerca de 40,6 milhões de dólares. Segundo Feldberg et al. (2008), esta importação deve-se principalmente à pequena área cultivada com videiras sem semente (as mais indicadas para uva-passa) no país, gerando baixa oferta deste tipo de uva para a desidratação na forma de passas.

A produção de uva-passa é uma alternativa para redução da importação, assim como redução de perdas pós-colheita. Segundo Costa et al. (2015), utilizar bagas excedentes e também as com qualidade para fins de produção de uva-passa pode permitir tais reduções, sendo uma alternativa de mercado para os produtores de uva de mesa.

De acordo com Feiden et al. (2015), a secagem ou desidratação é uma técnica de conservação que reduz o conteúdo de água da fruta ou do vegetal, minimizando a possibilidade de deterioração microbiana, transformação enzimática e oxidação, sem perdas da cor, aroma, sabor e textura. Para obtenção da uva-passa, os frutos passam pelo processo de secagem ou desidratação.

A produção de passas no semiárido ainda precisa ser explorada, mesmo sendo uma região promissora na atividade. Neste sentido, objetivou-se estudar as características físicas, químicas e sensoriais de uvas 'Vitória', 'Niágara Branca' e 'Benitaka' desidratadas, produzidas no semiárido.

\section{Material e métodos}

Foram utilizadas uvas das cultivares BRS Vitória, Benitaka (Vitis vinifera) e Niágara Branca (Vitis labrusca), provenientes de parreiral comercial do município de Nova Porteirinha-MG. A colheita se deu no mês de novembro de 2016 e os cachos apresentavam-se sem danos físicos (injúrias) e com o grau de maturidade comercial adequado para o processamento, ou seja, firmes e maduras, considerando-se o mínimo de $14^{\circ}$ Brix, segundo a legislação (BRASIL, 2002). Após colhidos, os frutos foram levados para o laboratório de Tecnologia de Produtos de Origem Vegetal (TPOV) da Universidade Estadual de Montes Claros, Janaúba, e, antes do processamento, foram avaliados quanto aos parâmetros pH, acidez titulável e sólidos solúveis. $\mathrm{O}$ pH foi obtido por potenciometria. A acidez titulável, determinada por titulação e expressa em gramas de ácido tartárico por $100 \mathrm{~g}$ de polpa. A avaliação de sólidos solúveis foi feita por leitura direta em refratômetro manual/digital, com resultados expressos em ${ }^{\circ}$ Brix (IAL, 2008).

Após a caracterização inicial das uvas, as mesmas foram levadas para secagem, realizada de forma individual para cada cultivar. Primeiramente, os cachos foram submetidos a uma lavagem e sanitização, em solução de hipoclorito de sódio na concentração de 20 ppm, por 15 minutos. Posteriormente, realizou-se uma degranagem e as uvas selecionadas foram pesadas, para obtenção de rendimento. Seguida à pesagem, as uvas foram dispostas em bandejas de aço inox telado e levadas para secagem. A secagem foi realizada em estufa de circulação de ar forçado com controle da temperatura do ar de secagem a $70^{\circ} \mathrm{C}$, por 24 horas (cultivar Vitória) e 32 horas ('Niágara' e 'Benitaka'). Esses tempos foram definidos a partir de um pré-teste, até a observação da desidratação das uvas dentro do teor de umidade exigido pela legislação. Além disso, durante os testes, observou-se a dificuldade de secagem das uvas 'Niágara', sendo necessário, então, submetê-las a um banho de $\mathrm{NAOH}$ 0,5\% por 10 segundos, com o objetivo de promover rachaduras, facilitando, assim, 
Avaliação sensorial e da qualidade de uvas-passas processadas a partir de três cultivares produzidas no semiárido Martineli, M. et al.

a secagem dessas uvas (ALBUQUERQUE et al. 1987). Após o tempo de secagem, as uvas-passas foram, então, retiradas das bandejas, resfriadas, pesadas e embaladas em recipiente plástico fechado para posteriores avaliações de grau de umidade, rendimento, pH, acidez titulável e sólidos solúveis e para análise sensorial. Na Figura 1, estão apresentadas as uvas in natura e após a desidratação.

A determinação da umidade se deu pela diferença entre a massa inicial da amostra e a massa final após aquecimento em estufa com circulação de ar a $105^{\circ} \mathrm{C}$ até massa constante, com valor expresso em porcentagem. O rendimento foi determinado pela relação entre a massa do fruto in natura e após secagem, em balança semianalítica, expresso em porcentagem [(peso do produto final $\times 100$ )/peso inicial]. $\mathrm{O} \mathrm{pH}$ foi obtido por potenciometria. A acidez titulável foi determinada por titulação com $\mathrm{NAOH} 0,1 \mathrm{~N}$ e expressa em gramas de ácido tartárico por $100 \mathrm{~g}$ de polpa. O teor de sólidos solúveis foi obtido por leitura direta em refratômetro manual/digital, com resultados expressos em ${ }^{\circ}$ Brix (IAL, 2008).

As uvas-passas foram avaliadas quanto à aceitação, de acordo com Meilgaard et al. (1999), tendo-se utilizado a escala hedônica de nove pontos, variando de: 1 - desgostei extremamente a 9 - gostei extremamente. Os consumidores observaram as uvas-passas e expressaram o quanto gostaram da aparência e da cor, e depois degustaram a amostra para expressaram o quanto gostaram da textura e do sabor. Paralelamente, aplicou-se uma intenção de compra, em que os participantes avaliaram as uvas-passas e responderam se comprariam o produto, com base na aparência, utilizando uma escala de cinco pontos, que variou de 1 - 'definitivamente não compraria' a 5 - 'definitivamente compraria'.

Cem participantes, entre eles funcionários, estagiários e alunos da Unimontes - Janaúba, com idade entre 18 e 60 anos, consumidores de uva-passa, foram convidados a participar do estudo. Ao aceitarem, foram encaminhados à sala de Análise Sensorial do Laboratório TPOV, para a realização dos testes. As amostras foram apresentadas monadicamente, seguindo delineamento balanceado, segundo Dutcovisky (2013). Foram servidas duas uvas em copos plásticos de $30 \mathrm{~mL}$, codificados com três números, à temperatura ambiente, sendo também colocada, à disposição dos provadores, água para enxaguar a boca.

O Delineamento Experimental aplicado, tanto para o estudo das uvas in natura, quanto após o processamento, foi o inteiramente casualizado - DIC, com três tratamentos (três cultivares de uvas) e sete repetições (cada repetição foi composta por três cachos).

Os dados físicos e químicos das uvas in natura e desidratadas foram submetidos à análise de variância (ANOVA) e, para verificar se as cultivares diferiram entre si, foi aplicado o Teste Tukey em nível de 5\% de probabilidade $(p<0,05)$. A umidade foi analisada por meio de estatística descritiva.

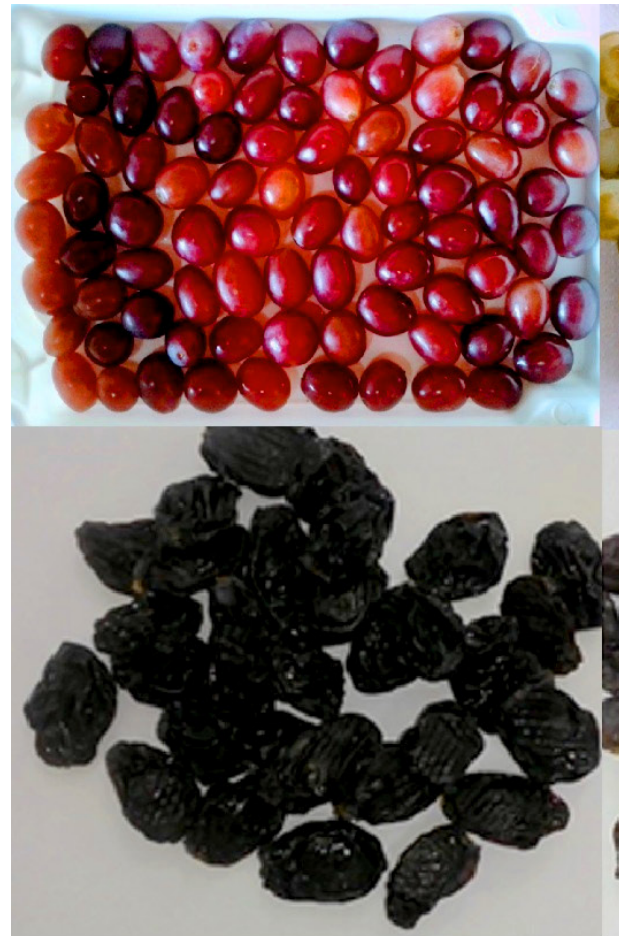

'BENITAKA'

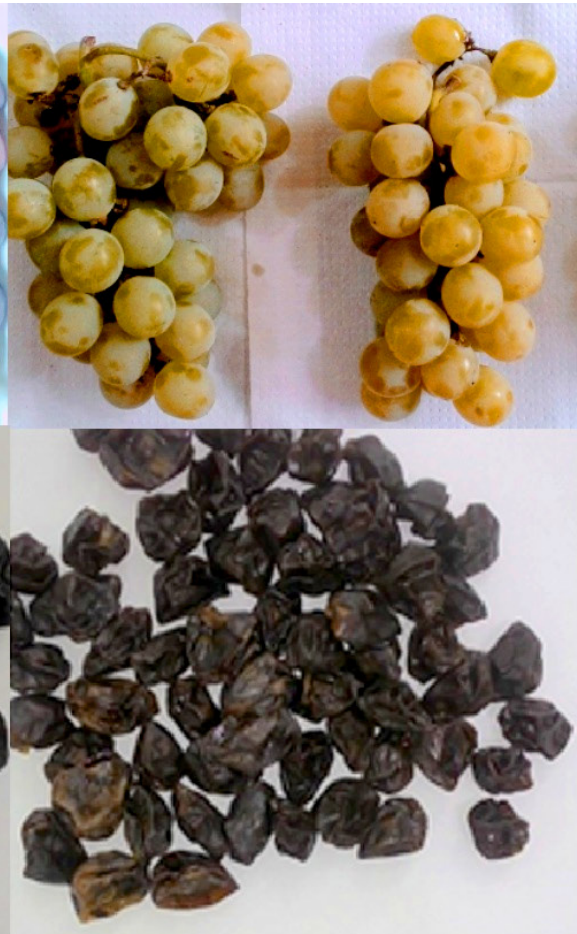

NIÁGARA BRANCA'

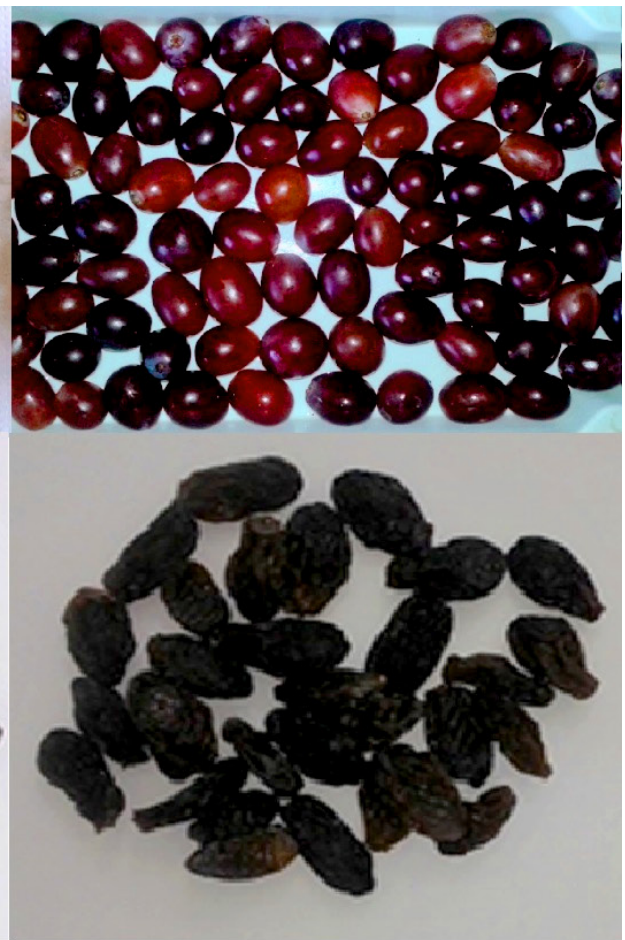

'VITÓRIA'

Figura 1. Uvas in natura e após o processamento. 
Nos dados da análise sensorial, para o teste de aceitação, utilizou-se uma estatística não paramétrica, uma vez que os dados não apresentaram normalidade e homogeinidade, aplicando-se o Teste de Kruskal-Wallis, em nível de $5 \%$ de significância $(p<0,05)$. Na intenção de compra, aplicou-se uma estatística descritiva nos dados.

\section{Resultados e discussão}

Este projeto foi submetido ao Comitê de Ética e Pesquisa da Universidade Estadual de Montes Claros, com parecer de aprovação número 2.073.199.

Na Tabela 1, encontram-se os resultados referentes aos componentes de qualidade das uvas in natura.

Para os dados de $\mathrm{pH}$ e acidez, houve diferença significativa entre as cultivares em estudo $(p<0,05)$. Verificaram-se os maiores valores de $\mathrm{pH}$ para a cultivar Benitaka, diferindo das demais cultivares. Para acidez titulável, a uva 'Niágara' apresentou conteúdo significativamente superior de ácido tartárico (Tabela 1). Mascarenhas et al. (2010) e Maia e Camargo (2009) reportaram acidez superior ao do presente estudo em uvas Benitaka e Niágara Branca.

Quanto ao conteúdo de sólidos solúveis, as cultivares não diferiram entre si $(p>0,05)$, apresentando valores médios de 16,21 ${ }^{\circ}$ Brix, 17,41 ${ }^{\circ}$ Brix e 17,65 ${ }^{\circ}$ Brix, para Niágara, Vitória e Benitaka, respectivamente (Tabela 1). Segundo Lins et al. (2015), os sólidos solúveis dissolvidos na polpa têm como principais componentes os açúcares

Tabela 1. Valores de pH, acidez titulável e sólidos solúveis de uvas in natura produzidas no Semiárido.

\begin{tabular}{|c|c|c|c|}
\hline \multirow[b]{2}{*}{ Cultivares } & \multirow[b]{2}{*}{ pH } & Acidez titulável & $\begin{array}{l}\text { Sólidos } \\
\text { solúveis }\end{array}$ \\
\hline & & $\begin{array}{c}\text { (g ácido } \\
\text { tartárico. } \\
100 \mathrm{~g}^{-1} \text { amostra) }\end{array}$ & ( ${ }^{\circ}$ Brix) \\
\hline Vitória & $4,05^{b}$ & $0,48^{b}$ & $17,41^{a}$ \\
\hline Benitaka & $4,12^{a}$ & $0,44^{b}$ & $17,65^{a}$ \\
\hline Niágara Branca & $3,99^{c}$ & $0,55^{a}$ & $16,21^{a}$ \\
\hline Média Geral & 4,05 & 0,49 & 17,11 \\
\hline CV (\%) & 0,86 & 7,20 & 7,02 \\
\hline
\end{tabular}

Médias seguidas da mesma letra na coluna não diferem entre si pelo Teste Tukey em nível de $5 \%$ de probabilidade $(p<0,05)$. solúveis, cuja concentração tende a aumentar com a maturação. No presente trabalho, o teor de sólidos solúveis encontrado na uva 'Benitaka' foi superior ao reportado por Santillo (2011) e Mascarenhas et al. (2010), que obtiveram respectivos teores de sólidos solúveis de 14,0 ${ }^{\circ}$ Brix e 13,63 ${ }^{\circ}$ Brix, nesta mesma cultivar. Maia e Camargo (2009) citaram teor médio de sólidos solúveis em uva 'Niágara Branca' de 16,9 `Brix, valor próximo ao do presente estudo. Segundo Maia et al. (2012), uvas 'Vitória' produzidas em regiões tropicais podem apresentar teor de sólidos solúveis superior a $23^{\circ}$ Brix. De acordo com Leão (2004), a composição química da uva, caso não haja excesso de precipitação pluvial, é influenciada pela temperatura, uma vez que quanto mais elevada for a temperatura da região de cultivo, dentro dos limites críticos, maior será a concentração de açúcar e menor a de ácido málico nos frutos, corroborando com o obtido no presente estudo, considerando-se as altas temperaturas na região $\left(27^{\circ} \mathrm{C}\right.$ a $\left.40^{\circ} \mathrm{C}\right)$, que coincidem com a época de maturação das bagas, favorecendo a degradação de ácidos orgânicos presentes.

$\mathrm{Na}$ Tabela 2, encontram-se os resultados físicos e químicos das uvas-passas.

Para o grau de umidade das diferentes cultivares de uva estudadas, os valores do presente trabalho encontram-se dentro do padrão de determinação da legislação, segundo a qual é aceitável o limite de até $25 \%$ de umidade em frutas desidratadas (BRASIL, 2005), atendendo, ainda, o CODEX STAN 67 (INMETRO, 1981), que preconiza que a umidade em uvas sem grainha (sem sementes) não ultrapasse $18 \%$. Após o processamento, a umidade das uvas-passas permaneceu na faixa de 5,73\% a 9,24\%. Esse teor de água permite estender a vida de prateleira deste produto, evitando, assim, o desenvolvimento de microrganismos favorecidos por teores de umidade mais elevada (NORTHOLT et al., 1978).

Houve diferença significativa nos parâmetros rendimento, $\mathrm{pH}$, acidez titulável e sólidos solúveis das uvas-passas obtidas das diferentes cultivares $(p<0,05)$ (Tabela 2).

Quanto ao rendimento, a uva 'Niágara Branca' após secagem apresentou maior rendimento, diferindo das demais. De acordo com Jesus et al. (2005), o rendimento

Tabela 2. Valores de umidade, rrendimento, pH, acidez titulável e sólidos solúveis de uvas-passas de cultivares produzidas no Semiárido.

\begin{tabular}{|c|c|c|c|c|c|}
\hline \multirow{2}{*}{ Cultivares } & Umidade & Rendimento & \multirow{2}{*}{ pH } & Acidez Titulável & Sólidos Solúveis \\
\hline & $(\%)$ & $(\%)$ & & (g ácido tartárico. $100 \mathrm{~g}^{-1}$ amostra) & ( ${ }^{\circ}$ Brix) \\
\hline Vitória & 9,24 & $21,94^{b}$ & $5,56^{a}$ & $0,82^{b}$ & $67,28^{b}$ \\
\hline Benitaka & 5,73 & $20,83^{b}$ & $4,71^{b}$ & 1,28 a & $81,60^{a}$ \\
\hline Niágara Branca & 7,69 & $37,62^{a}$ & $4,50^{\circ}$ & $0,88^{b}$ & $63,62^{b}$ \\
\hline Média Geral & & 26,80 & 4,93 & 0,99 & 71,02 \\
\hline CV $(\%)$ & & 19,53 & 2,25 & 9,90 & 7,25 \\
\hline
\end{tabular}

Médias seguidas da mesma letra na coluna não diferem entre si pelo Teste Tukey em nível de $5 \%$ de probabilidade $(p<0,05)$. 
Avaliação sensorial e da qualidade de uvas-passas processadas a partir de três cultivares produzidas no semiárido Martineli, M. et al.

do produto apresenta uma relação direta com a perda de água e a absorção de açúcares; no entanto, menor porcentagem de água foi observada nas uvas-passas provenientes da cultivar Benitaka.

Para os resultados de $\mathrm{pH}$, observou-se valor significativamente superior nas uvas-passas provenientes da cultivar Vitória, seguida da Benitaka e Niágara Branca. Em relação à acidez titulável, a concentração de ácido tartárico nas uvas-passas advindas da cultivar Benitaka apresentou-se estatisticamente superior às concentrações das uvas 'Vitória' e 'Niágara'. Esse resultado está atribuído à menor umidade presente nas uvas-passas de uvas 'Benitaka', que tiveram, como consequência, maior concentração de ácidos.

De forma semelhante à acidez titulável, o teor de sólidos solúveis nas uvas-passas obtidas pela cultivar Benitaka foi significativamente superior aos teores das demais. A concentração de açúcares está associada à redução de água no fruto; logo, uvas-passas com menor umidade ('Benitaka') concentraram mais açúcares e ácidos no final da secagem, gerando um produto mais doce e ácido. Segundo Santos et al. (2011), os sólidos solúveis são uma das características mais relevantes do ponto de vista das indústrias processadoras de frutos, pois mede, indiretamente, o teor de açúcares do fruto. As uvas-passas obtidas do processamento da cultivar Benitaka do atual estudo foram superiores, no que tange ao reportado por Feldberg et al. (2008) em uvas-passas processadas a partir das cultivares Superior Seedless,
Catalunha, Sultanina e Crimson Seedless, também cultivadas no norte de Minas Gerais.

Os dados referentes aos testes sensoriais estão apresentados na Figura 2 (intenção de compra) e na Tabela 3 (aceitação).

Em relação à intenção de compra, com base na aparência, observa-se que $46 \%$ dos consumidores declararam que não comprariam as uvas-passas obtidas da cultivar Niágara Branca, 39\% demonstraram-se indecisos e somente $15 \%$ comprariam este produto, denotando rejeição por parte dos consumidores (Figura 2). Em contrapartida, 56\% e $52 \%$ dos participantes declararam que comprariam as uvas-passas 'Vitória' e 'Benitaka', respectivamente; 37\% e $36 \%$ talvez comprassem, talvez não comprassem, e apenas $8 \%$ e $13 \%$ rejeitaram estes respectivos produtos.

Tabela 3. Médias das notas atribuídas pelos provadores (100) na aceitação de uvas-passas (escala hedônica que variou de 1 = desgostei extremamente a 9 = gostei extremamente).

\begin{tabular}{lcccc} 
Cultivares & $\begin{array}{c}\text { Aparência } \\
\text { geral }\end{array}$ & Cor & Textura & Sabor \\
Vitória & $6,64^{\mathrm{a}}$ & $6,77^{\mathrm{b}}$ & $7,02^{\mathrm{a}}$ & $6,98^{\mathrm{a}}$ \\
Benitaka & $6,83^{\mathrm{a}}$ & $7,29^{\mathrm{a}}$ & $6,69^{\mathrm{a}}$ & $7,02^{\mathrm{a}}$ \\
Niágara & $4,43^{\mathrm{b}}$ & $4,69^{\mathrm{c}}$ & $3,89^{\mathrm{b}}$ & $4,39^{\mathrm{b}}$ \\
Média & $5,97^{\mathrm{a}}$ & $6,25^{\circ}$ & 5,87 & 6,13 \\
\hline
\end{tabular}

Médias seguidas da mesma letra, na coluna, não diferem entre si pelo de Teste Kruskal- Wallis a $5 \%$ de probabilidade $(p<0,05)$.

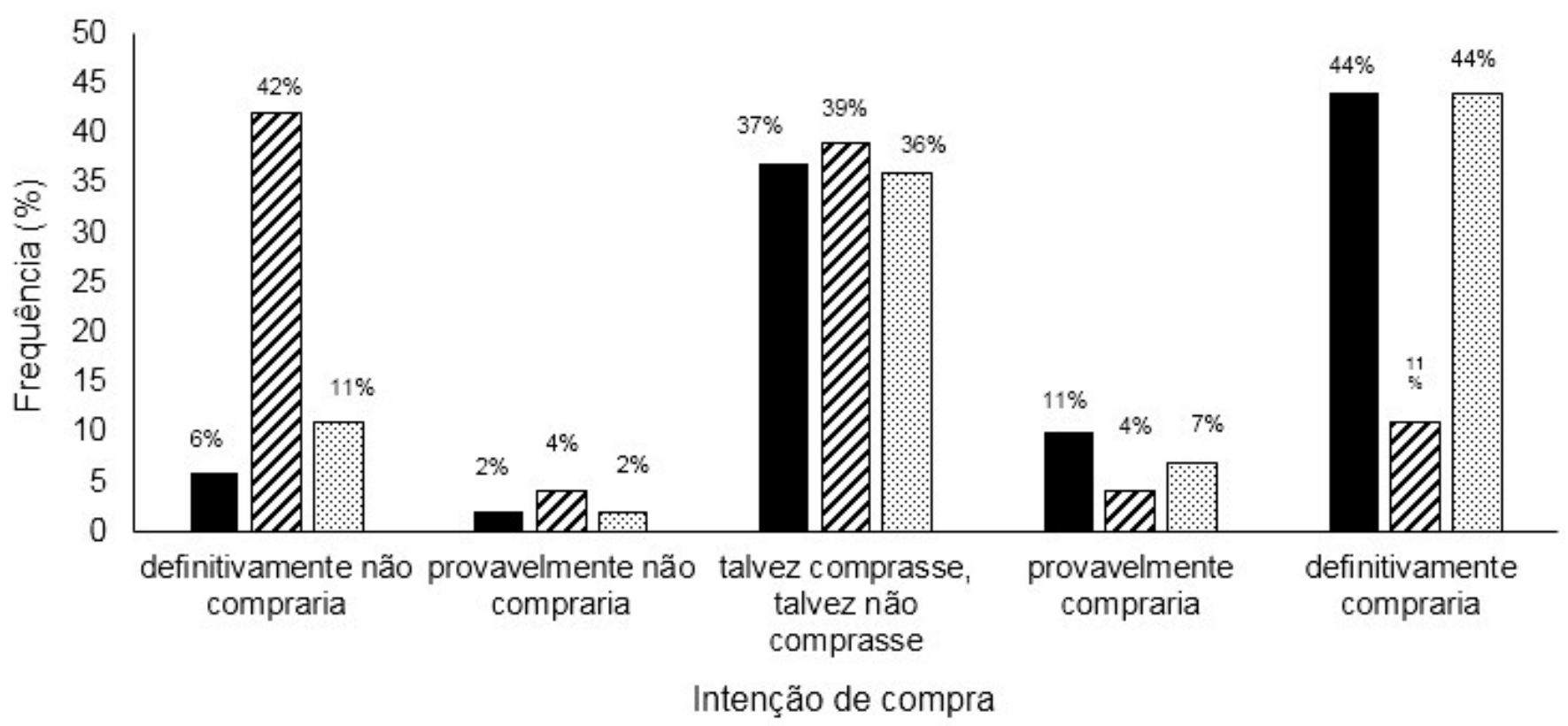

- 'Vitória'

ఐ'Niágara Branca'

ஐ'Benitaka'

Figura 2. Distribuição da frequência das notas de intenção de compra de 100 consumidores: escala estruturada de 5 pontos, que variou de "definitivamente não compraria" (1) a "definitivamente compraria" (5). 
Na aceitação sensorial das uvas-passas, considerou-se o produto "aceito pelo consumidor" para notas acima de 5 (QUEIROZ et al., 2007). Assim, é possível observar aceitação do produto em relação a todos os atributos das uvas-passas processadas a partir das cultivares 'Vitória' e 'Benitaka', e rejeição da uva-passa 'Niágara Branca'.

Quanto à aparência, quando convidados a descrever o que mais desgostaram do produto, 19\% dos participantes declararam que a aparência da uva-passa proveniente da uva 'Niágara Branca' era 'ruim' (dados não apresentados), uma provável explicação do baixo interesse de compra desse produto (Figura 2). Alves et al. (2010) citaram que a aparência é o principal fator que leva os consumidores a aceitarem um alimento. Também, Chitarra e Chitarra (2005) citaram que as características externas de qualidade atuam na diferenciação do produto, importantes na decisão de compra. Santillo (2011) obteve resultado semelhante em uvas-passas escuras, com média de aceitação de 6,23. Já as uvas-passas Festival (Superior Seedless) processadas por Lima (2012) obtiveram média de aceitação inferior ao do presente estudo para as passas das cultivares Vitória e Benitaka.

Em relação ao atributo cor, ao descreverem o que mais gostaram e/ou desgostaram nas uvas-passas, 15\% dos consumidores declararam a cor das passas oriundas das uvas 'Benitaka' como atrativa, seguida de 12\% para as passas da uva 'Vitória', indicando uma preferência por uvas-passas mais escuras e uniformes, como as originadas da cultivar Benitaka. Resultado semelhante foi relatado por Lima (2012), que também observou em seu trabalho com uvas-passas tratadas com diferentes agentes clarificantes que a maior aceitação se deu pelas passas mais escuras do tratamento controle. O autor explica que este resultado pode estar associado ao fato de que o consumidor local, normalmente, está acostumado a consumir uvas-passas escuras, vindo a influenciar em seu julgamento.

Sobre a aceitação da textura, como já descrito anteriormente, as maiores médias foram obtidas pelas cultivares Vitória e Benitaka, significativamente superiores à cultivar Niágara Branca. Dos 100 participantes do teste, $48 \%$ descreveram não gostar da textura devido à presença de sementes, o que pode explicar a baixa média obtida na aceitação deste referido produto. Por outro lado, a presença de sementes nas uvas-passas provenientes das uvas 'Benitaka' parece não ter interferido no julgamento dos participantes, pois, apesar de 47\% terem expressado não gostar da presença das sementes, ainda assim aceitaram o produto (média 6,69). Segundo Chitarra e Chitarra (2005), a textura é um dos atributos de qualidade de maior importância, visto que o conjunto das impressões obtidas na mastigação é decisivo para a aceitação ou rejeição de um produto. Pangavhane et al. (1999), em um estudo com uvas-passas emergidas em diferentes soluções que antecederam à secagem, observaram médias relativas a "gostei moderadamente" (também observadas no presente estudo) e "gostei muito".

Sobre a aceitação do sabor das uvas-passas processadas a partir de uvas 'Vitória' e 'Benitaka', 57\% e $50 \%$ dos consumidores descreveram, respectivamente, o sabor destes produtos como "gostoso/doce", contra 24\% para as passas da cultivar Niágara Branca. Chitarra e Chitarra (2005) relataram que as características internas, combinadas com a aparência, são importantes na determinação da aceitação do produto, justificando, assim, a rejeição da uva-passa obtida pela cultivar Niágara.

Em um estudo com uvas-passas 'Fiesta' e 'Selma Pete', Angulo et al. (2007) relataram inferiores médias de aceitação referentes ao sabor, quando comparadas com as passas das cultivares 'Vitória' e 'Benitaka', no presente estudo. De acordo com Celestino (2010), quando uma fruta é submetida à desidratação, ocorre a concentração do seu açúcar natural, obtendo-se, como consequência, um produto com sabor e cor acentuados. Essa afirmação pode explicar a boa aceitação da uva-passa proveniente da cultivar Benitaka, que apresentou maiores teores de sólidos solúveis entre os produtos das três cultivares estudadas (Tabela 2). Com esse resultado, é possível inferir que uvas 'Vitória' e 'Benitaka' permitem a obtenção de uvas-passas com qualidade e aceitas pelos consumidores, diversamente da cultivar Niágara Branca, que gera um produto menos doce, aparência não atrativa e textura prejudicada pela presença de sementes. Dessa forma, pode-se definir as cultivares 'Vitória' e 'Benitaka' como cultivares com potencial de processamento através da desidratação, tornando-se uma alternativa ao produtor para aumentar a renda e reduzir perdas durante e após a colheita.

\section{Conclusões}

Uvas-passas originadas das cultivares 'Benitaka' e 'Vitória', mesmo com diferentes conteúdos de sólidos solúveis e acidez titulável após a desidratação, apresentam maior qualidade, sendo aceitas pelos consumidores. Além do sabor, os consumidores gostam mais da aparência e textura das uvas-passas processadas a partir das cultivares Benitaka e Vitória, e rejeitam as provenientes da 'Niágara Branca'.

\section{Agradecimento}

\section{à Pesquisa.}

À FAPEMIG, pela concessão da Bolsa de Incentivo

\section{Referências}

AlBUQUERQUE, T. C. S.; ALBUQUERQUE, J. A. S.; VIEIRA, S. M. N. S. Processamento de uvas-passas na região semiárida do Nordeste. Brasília: EMBRAPA-CPATSA, 1987. p. 1-4. (Comunicado Técnico 21). 
Avaliação sensorial e da qualidade de uvas-passas processadas a partir de três cultivares produzidas no semiárido Martineli, M. et al.

ALVES, J. A.; VILAS BOAS, E. V. B.; VILAS BOAS, B. M.; SOUZA, É. C. Qualidade de produto minimamente processado à base de abóbora, cenoura, chuchu e mandioquinha-salsa. Food Science and Technology (Campinas), v. 30, n. 3, p. 625-634, 2010. http://dx.doi.org/10.1590/S0101-20612010000300009.

ANGULO, O.; FIDELIBUS, M. W.; HEYMANN, H. Grape cultivar and drying method affect sensory characteristics and consumer preference of raisins. Journal of the Science of Food and Agriculture, v. 87 , n. 5, p. 865-870, 2007. http://dx.doi. org/10.1002/jsfa.2790.

BRASIL. Ministério da Agricultura, Pecuária e Abastecimento. Instrução Normativa $n^{\circ} 1$ de $1^{\circ}$ de fevereiro de 2002. Regulamento técnico de identidade e de qualidade para a classificação da uva fina de mesa. Diário Oficial [da] República Federativa do Brasil, Brasília, DF, 04 fev. 2002, Seção 1. 7 p.

BRASIL. Agência Nacional de Vigilância Sanitária. Resolução RDC $n^{\circ} 272$ de 22 de setembro de 2005. Aprova o regulamento técnico para produtos de vegetais, produtos de frutas e cogumelos comestíveis. Diário Oficial [da] República Federativa do Brasil, Brasília, DF, 23 set. 2005.

CAMARgo, U. A.; TONIETto, J.; HOFFMANN, A. Progressos na viticultura brasileira. Revista Brasileira de Fruticultura, $v$. 33, n. 1, p. 144-149, 2011. http://dx.doi.org/10.1590/S010029452011000500017

CELESTINO, S. M. C. Princípios de secagem de alimentos. Planaltina: Embrapa Cerrados, 2010. 51 p. (Documentos 276).

CHITARRA, M. I. F.; CHITARRA, A. B. Pós-colheita de frutos e hortaliças: fisiologia e manuseio. 2. ed. rev. e ampl. Lavras: UFLA, 2005. 783 p.

COSTA, J. D. S.; FIGUEIREDO NETO, A.; NUNES, S. M.; RYBKA, A. C. P.; BIASOTO, A. C. T.; FREITAS, S. T. Caracterização física e físico-química de uva Itália desidratada. Revista Iberoamericana de Tecnología Postcosecha, v. 16, n. 2, p. 273-280, 2015.

DUTCOVISKY, S. D. Análise sensorial de alimentos. 4. ed. rev. e ampl. Curitiba: Champagnat, 2013. 540 p.

FEIDEN, A.; FEIDEN, A.; GALVANI, F.; CAMPOLIN, A. Desidratação de frutas utilizando secador solar. Corumbá: Embrapa Pantanal, 2015. 5 p. (Comunicado Técnico 98). Disponível em: <https://www. infoteca.cnptia.embrapa.br/infoteca/bitstream/doc/1037117/1/ COT98.pdf>. Acesso em: 07 mar. 2018.

FELDBERG, N. P.; MOTA, R. V.; SIMÕES, W. L.; REGINA, M. A. Viabilidade da utilização de descartes de produção de uvas sem sementes para elaboração de passas. Revista Brasileira de Fruticultura, v. 30, n. 3, p. 846-849, 2008. http://dx.doi. org/10.1590/S0100-29452008000300050.

HOFFMANN, A. Sistema de produção de uva de mesa no Norte de Minas Gerais. Brasília: Embrapa, 2005. Disponível em: <http://www.cnpuv.embrapa.br/publica/sprod/MesaNorteMinas>. Acesso em: 07 dez. 2016.
INMETRO. Norma del codex para las uvas pasas. Rio de Janeiro: Inmetro, 1981. (Codex Stan 67). Disponível em: <http:// www.inmetro.gov.br/barreirastecnicas/ExigenciasTecnicas/ documentos/ESP/CX\%2067\%20Uvas\%20pasas.pdf>. Acesso em: 21 jun. 2017.

INSTITUTO ADOLFO LUTZ - IAL. Métodos físico-químicos para análise de alimentos. São Paulo: Instituto Adolfo Lutz, 2008. p. 1020 p.

INSTITUTO BRASILEIRO DE GEOGRAFIA E ESTATÍSTICA - IBGE. Levantamento sistemático da produção agrícola - março 2017. Rio de Janeiro: IBGE, 2017. Disponível em: <https://sidra.ibge. gov.br/home/lspa/brasil>. Acesso em: 19 abr. 2017.

JESUS, S. C.; MATSUURA, F. C. A. U.; FOLEGATTI, M. I. S.; CARDOSO, R. L. Avaliação de banana-passa obtida de frutos de diferentes genótipos de bananeira. Pesquisa Agropecuária Brasileira, v. 40, n. 6, p. 573-579, 2005. http://dx.doi.org/10.1590/ S0100-204X2005000600007.

LEÃO, P. C. S. Cultivo da videira. Brasília: EMBRAPA-CPATSA, 2004. Disponível em: http://www.cpatsa.embrapa.br:8080/ sistema_producao/spvideira/cultivares.htm>. Acesso em: 16 maio 2017

LIMA, M. S. Estudo dos atributos sensoriais de uva passa submetida a tratamentos para manutenção da cor pós-secagem. In: VII CONNEPI - CONGRESSO NORTE NORDESTE DE PESQUISA E INOVAÇÃO, 7., 2012, Palmas. Anais... Tocantins: IFTO, 2012. 7 p.

LINS, A. D. F.; ROQUE, I. M. B.; LISBOA, C. G. C.; FEITOSA, R. M. COSTA.D.S. Qualidade durante o desenvolvimento de uvas viníferas 'Syrah'do Submédio do Vale São Francisco. Agropecuária Técnica, v. 36, n. 1, p. 259-263, 2015.

MAIA, J. D. C.; CAMARGO, U. A. Sistema de produção de uvas rústicas para processamento em regiões tropicais do Brasil. Brasília: Embrapa, 2009. Disponível em: <https:// sistemasdeproducao.cnptia.embrapa.br/FontesHTML/Uva/ UvasRusticasParaProcessamento/cultivares.htm >. Acesso em: 16 maio 2017.

MAIA, J. D. G.; RITSCHEL, P. S.; CAMARGO, U. A.; SOUZA, R. T.; FAJARDO, T. V. M.; NAVES, R. L.; GIRARDI, C. L. BRS Vitória: nova cultivar de uva de mesa sem sementes com sabor especial e tolerante ao míldio. Brasília: Embrapa, 2012. (Comunicado Técnico 126). Disponível em: <http://www.cnpuv.embrapa.br/ pesquisa/pmu/Comunicado_Tecnico_126.pdf>. Acesso em: 16 maio 2017.

MASCARENHAS, R. J.; SILVA, S. M.; LOPES, J. D.; LIMA, M. A. C. Avaliação sensorial de uvas de mesa produzidas no Vale do São Francisco e comercializadas em João Pessoa-PB. Revista Brasileira de Fruticultura, v. 32, n. 4, p. 993-1000, 2010. http:// dx.doi.org/10.1590/S0100-29452011005000012.

MATTOS, G. N.; SANTOS, D. A.; TORREZAN, R.; TONON, R. V.; FURTADO, A. A. L.; CABRAL, L. M. C. Efeito antimicrobiano do extrato de bagaço de uva microencapsulado em salsichas 
Avaliação sensorial e da qualidade de uvas-passas processadas a partir de três cultivares produzidas no semiárido Martineli, M. et al.

de pescado. In: CONGRESSO BRASILEIRO DE CIÊNCIA E TECNOLOGIA DE ALIMENTOS, 20., 2016, Gramado. Anais... Porto Alegre: FAURGS, 2016.

MEILGAARD, M.; CIVILLE, G. V.; CARR, B. T. Sensory evaluation techniques. 3rd. ed. Boca Raton: CRC Press, 1999. 354 p. http:// dx.doi.org/10.1201/9781439832271.

MELLO, L. M. R. Desempenho da vitivinicultura brasileira em 2015. Brasília: Embrapa, 2016. Disponível em: <https:// www.embrapa.br/busca-de-noticias/-/noticia/9952204/artigodesempenho-da-vitivinicultura-brasileira-em-2015>. Acesso em: 20 abr. 2017.

NORTHOLT, M. D.; VAN EGMOND, H. P.; PAULSCH, W. E. Patulin production by some fungal species in relation to water activity and temperature. Journal of Food Protection, v. 41, n. 11, p. 885-890, 1978. http://dx. doi.org/10.4315/0362-028X-41.11.885.

PANGAVHANE, D. R.; SAWHNEY, R. L.; SARSAVADIA, P. N. Effect of various dipping pretreatment on drying kinetics of Thompson seedless grapes. Journal of Food Engineering, v. 39, n. 2, p. 211-216, 1999. http://dx. doi.org/10.1016/S0260-8774(98)00168-X.

QUEIROZ, V. A. V.; BERBERT, P. A.; MOLINA, M. A. B.; GRAVINA, G. A.; QUEIROZ, L. R.; DELIZA, R. Desidratação por imersãoimpregnação e secagem por convecção de goiaba. Pesquisa Agropecuária Brasileira, v. 42, n. 10, p. 1479-1486, 2007. http:// dx.doi.org/10.1590/S0100-204X2007001000016.

SANTILLO, A. G. Efeitos da radiação ionizante nas propriedades nutricionais das uvas de mesa Benitaka e uvas passas escuras. 2011. 96 f. Dissertação (Mestrado em Tecnologia Nuclear)--Universidade de São Paulo, São Paulo, 2011.

SANTOS, E. H. B.; AZEVEDO, L. C.; BATISTA, F. P. R.; MATOS, L. P.; LIMA, M. S. Caracterização química e sensorial de uvas desidratadas, produzidas no Vale do São Francisco para infusão. Revista Semiárido De Visu, v. 1, n. 2, p. 134-147, 2011.

VITIBRASIL. Dados da vitivinicultura. Brasília: Embrapa, 2016. Disponível em: <http://vitibrasil.cnpuv.embrapa.br/index.php?s opcao=sopt_05\&opcao=opt_05 >. Acesso em: 13 dez. 2016. 